\title{
PRODUCTION OF SEAWEED DERIVED BIOPLASTICS
}

\author{
Uldis Zaimis, Sintija Ozolina, Roberts Jurmalietis \\ Liepaja University, Latvia \\ uldis.zaimis@liepu.lv, sintijamiezite@gmail.com, roberts.jurmalietis@liepu.lv
}

\begin{abstract}
Since worldwide distribution of non-degradable plastic waste causes serious environmental pollution, growing efforts have been made to replace traditional petroleum derived plastics with biological ones. The present paper focuses on seaweed (macroalgae) detritus as a potential feedstock for bioplastic production, since significant quantities of seaweed residues are available in the research site - Kurzeme coast (Western Latvia). This study aims to adapt the method for polylactic acid (PLA) plastics manufacturing from red seaweed Furcellaria lumbricalis (black carrageen) and to manipulate properties of the plastic material produced. Furcellaria material has been gathered on Kurzeme coast in Liepaja city and brought to the Liepaja University for carrageenan substances isolation/separation. The samples were thoroughly washed with tap water, then boiled for 2 hours and hot filtered into cold isopropanol and subsequently blended with plasticizers (glycerine, potato starch, seaweed particles) in order to achieve the desirable physical and thermomechanical properties of the carrageenan product. At the end, the samples were dried at temperature $25^{\circ} \mathrm{C}$ for 24 hours. Carrageenan material was improved through combining two plasticizers (potato starch and glycerine) - bioplastic was suitable now for manufacturing spoons, cups, packaging boxes, etc. Still, research results should be considered as preliminary ones - further studies are necessary to develop compatible bioplastic from Furcellaria.
\end{abstract}

Keywords: bioplastics, carrageenan, plasticizers, seaweeds, Furcellaria lumbricalis.

\section{Introduction}

Mass production of petroleum-based plastics has caused also intense generation of harmful plastic trash; as a result, plastics belong now to key environmental pollutants - huge amount of slowly decomposing plastic waste has accumulated in biosphere. It has been estimated, e.g., that 60-99 million metric tonnes of mismanaged plastic waste have been produced and released worldwidely in 2015 alone [1]. Plastic waste causes unfavourable aquatic habitat alterations, releases and adsorbs chemical compounds of concern, makes harm to animals through ingestion and entanglement, etc. (see [2]). Accordingly, there is an urgent need to find environmentally sound and healthy substitutes for plastics, and the so-called bioplastics represent themselves as one of the alternatives.

Bioplastics are defined as plastics that are made fully or partially from biomass sources (e.g., wood chips, vegetable oils, corn starch, etc.), and have the identical function as the petroleum-based plastics [3]. Generally, bioplastics are divided into three main groups [4]: 1) bio-based but non-compostable plastics, e.g., polypropylene (PP), polyethylene terephthalate (PET), polytrimethylene terephthalate (PTT), thermoplastic polyester elastomer (TPC-ET), 2) bio-based degradable plastics, e.g., polylactic acid (PLA), polyhydroxyalkanoates (PHAs), cellulose-based plastics, and 3) fossil resources-based plastics that are biodegradable: polybutylene adipate terephthalate (PBAT). However, when discussing use of bioplastics, it should be taken into account that bioplastics manufacturing increases pressure on agricultural land. Accordingly, different organic waste (like food residues, sewage sludge, agricultural litter, etc.) could be considered as an exceptionally profitable feedstock. The current paper focuses on bioplastic manufacturing from particularly promising bio-waste - from dead seaweeds.

Seaweed communities on Western Latvia coast (the site of the current research) are represented predominantly by black carrageen Furcellaria lumbricalis populations. Dead carrageen is washed ashore by waves and frequently piles up on a seashore and, accordingly, has been perceived as an annoying garbage by local community (according to rough calculations, about 300-400 tons of seaweed detritus have been removed from Liepaja beach annually [5]). Nevertheless, dead seaweed biomass could be recognized not as a waste but, on the contrary, as an underestimated valuable multipurpose feedstock for biogas, ethanol, agar, cosmetic products, bioplastics, etc. manufacturing ("waste-toresource approach").

\section{Materials and methods}

Furcellaria lumbricalis biomass was collected on the Baltic Sea coast near Liepaja city (Western Latvia). Seaweed samples were thoroughly washed with tap water and then boiled for 2 hours, 
subsequently hot filtered into cold $\left(7^{\circ} \mathrm{C}\right)$ isopropanol and afterwards blended with glycerin and potato starch. Finally, the samples were dried at temperature $25^{\circ} \mathrm{C}$ for 24 hours.

The following ingredients were taken for bioplastic production: $600 \mathrm{~g}$ of washed seaweed, $31 \mathrm{of}$ water, $40 \mathrm{ml}$ cold $\left(7^{\circ} \mathrm{C}\right)$ isopropanol $(99.9 \% \mathrm{v} / \mathrm{v})$ for extraction, $40 \mathrm{~g}$ potato starch and $15 \mathrm{ml}$ glycerin (as plasticizers).

\section{Rationale behind: Purification and extraction process}

There is a common algorithm for extraction and processing of various carrageenan types - as a rule, the methodology always includes removal of impurities, separation of the carrageenan from the aqueous extraction medium and other constituents, drying to get the final product. Raw material for $\kappa$ carrageenan manufacturing can be obtained from different seaweed species like Eucheuma, Chondrus, Hypnea, Iridaea and Furcellaria [6].

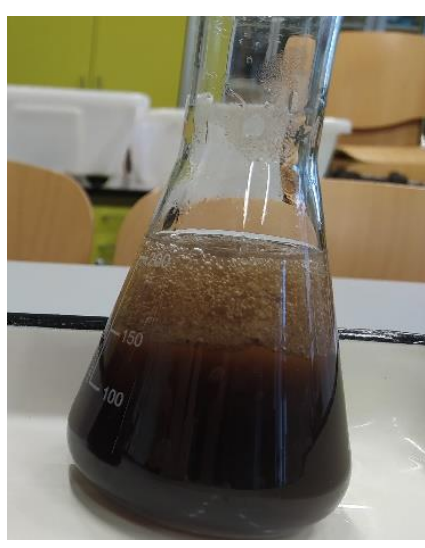

Fig. 1. Carrageenan located at the top of the flask

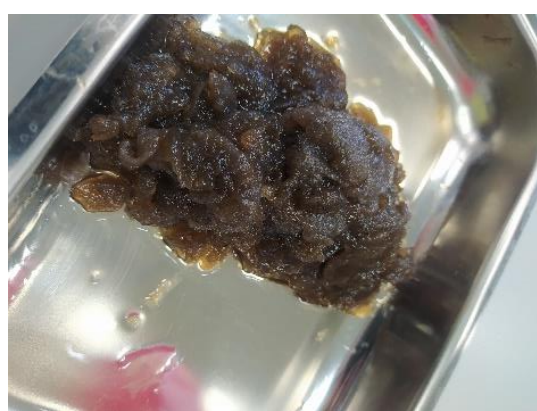

Fig. 2. Isolated polysaccharide mixture before drying

Carrageenan has to be extracted using hot alkali ( $\mathrm{KOH}$ or $\mathrm{NaOH}$ solutions) and then hot filtered through a porous glass filter into cold $\left(7^{\circ} \mathrm{C}\right)$ isopropanol $(99.9 \% \mathrm{v} / \mathrm{v})$ which will result in precipitation of polysaccharides (see Fig.1). The isolated polysaccharide mixture (Fig.2) could be dried to a constant weight in a drying oven $\left(60^{\circ} \mathrm{C}, 2\right.$ days) and then milled, for later usage, or immediately submitted to further processing [7].

Our research experience demonstrates that alkali treatment has a little impact on the extraction process - accordingly, carrageenan separation has been carried out exclusively through material boiling and isopropanol filtering.

\section{Rationale behind: Plasticizers}

Carrageenans can be blended with a range of different polymers like starch and various proteins, in order to obtain desired film properties. The adequate choice of plasticizer is of particular importance to achieve desirable physical and thermomechanical properties for each final application.

Polyols (mostly glycerol, sorbitol, polyethylene glycol PEG) have been extensively used as plasticizers in the production of many bioplastics [8].

Background considerations: plasticizers constitute about $45 \%$ of the bulk of the available bioplastic materials in the market. Functional role of plasticizer additives reveal through improving flexibility of polymer films, maintaining integrity of material, avoiding cracks and pores in a matrix. However, mutual incompatibility is possible and is usually evidenced by physical separation between polymer substratum and plasticizer [9].

Nowadays, particular interest has been focused on natural-based plasticizers which are environment and health friendly - like epoxidized triglyceride vegetable oils (from soybean oil, linseed oil, castoroil, sunflower oil), fatty acid esters (FAEs) [10].

\section{Results and discussion}

The study has been performed to adapt the method for PLA plastics manufacturing, as well as to reveal correlations between the plasticizer used and the properties of seaweed bioplastic. Glycerine 
plasticizer addition made bioplastic more flexible (see Table 1), however, the initial tests indicated bioplastic film being too soft and flexible with leaving too much glycerine residue on the surface (see Fig. 3). Accordingly, the material obtained was not considered as a useful product and was remelted at temperature $140{ }^{\circ} \mathrm{C}$ for enhancement manipulations. After adding potato starch and glycerine at the last stage of this treatment the carrageenan mixture quality was improved: the new material became harder after drying; when being still semi-fluid, it could be poured into a mould to manufacture, e.g., spoons, cups, packaging boxes.

However, the latter material (see Fig.4) is no more meltable. Both materials dilute in water, but not in acetone.

An extra experiment with the remelted material was performed by adding separate parts of seaweed, which made the material even harder and more durable, but more visually unattractive (see Fig. 5).

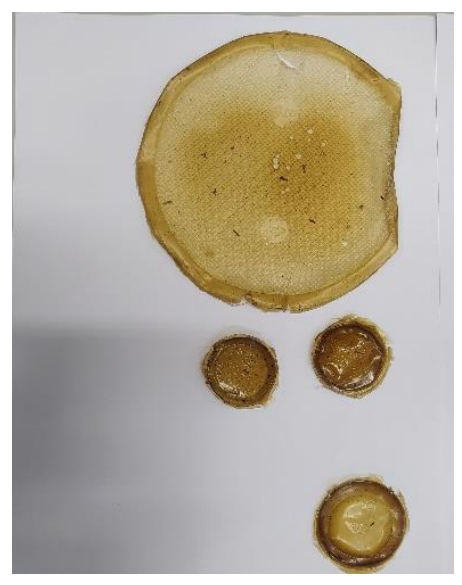

Fig. 3. Material with glycerine drops

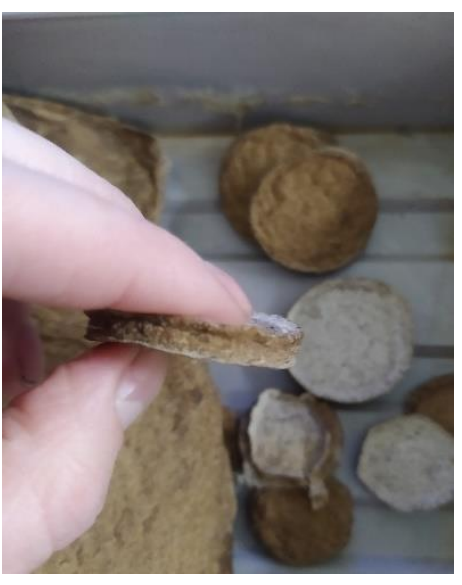

Fig. 4. Material with added glycerine and potato starch

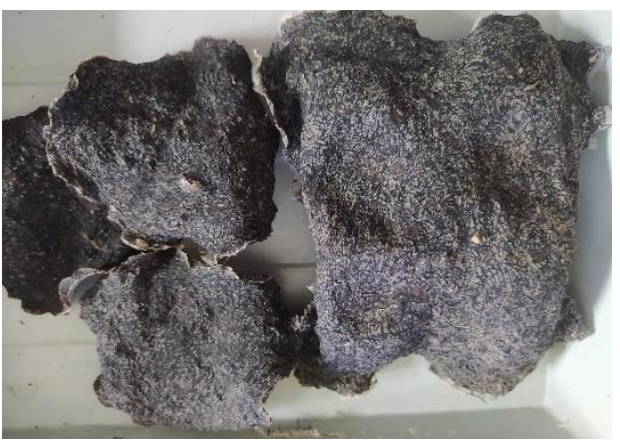

Fig. 5. Material with added glycerine, potato starch and seaweed particles

Flexibility of seaweed bioplastic

Table 1

\begin{tabular}{|c|c|c|c|c|}
\hline Sample & Added glycerin, $\mathbf{g}$ & Initial length, cm $^{* *}$ & Final length, $\mathbf{~ c m}$ & Extension, \% \\
\hline 1 & 14.4 & 5 & 6.5 & 30 \\
\hline 2 & 7.2 & 5 & 6.1 & 22 \\
\hline 3 & 2.0 & 5 & 5.8 & 16 \\
\hline
\end{tabular}

* Amount of extracted carrageenan $-72 \mathrm{~g}$

** 1 x $5 \mathrm{~cm}$ rectangle - stretch until burst

The results of the experimental study demonstrated that the method adapted for seaweed treatment is appropriate for low-input bioplastic manufacturing. Besides, adding selected plasticizers improved the physical properties of the bioplastic film. Nevertheless, these results are still preliminary - further research is needed to develop useful bioplastic and to make relevant comparisons with other bioplastic production directed studies. Competitive advantage of the current project is related to the particular feedstock chosen - dead seaweed is a cheap, readily available resource in Latvia.

\section{Conclusions}

1. Seaweed Furcellaria lumbricalis represents itself a promising material for bioplastics production in Latvia - according to rough estimates, about $50 \mathrm{t}$ of dead seaweed could be gathered along the Kurzeme coast.

2. Bioplastic manufactured within the present study can be used for food or other product packaging; this bioplastic is a priori evaluated as being not harmful to the environment and health.

3. Carrageenan material quality was improved when adding selected plasticizers - potato starch and glycerine ( $20 \%$ glycerine added appeared to be the most advantageous amount to improve elasticity of bioplastic).

4. Further research is needed to make the final material suitable for practical use. 
5. Besides economic gains, Furcellaria lumbricalis bioplastic projects would facilitate the Baltic Sea coastal environment quality improvement through beach cleaning from seaweed waste.

\section{Acknowledgements}

This work was carried out within partial financial support from the European Regional Development Fund Project No. 1.1.1.5/018 "Promotion of research, innovation and international cooperation in science at Liepaja University".

\section{References}

[1] Lebreton L., Andrady A.L. Future scenarios of global plastic waste generation and disposal, Palgrave Communications 5(1), 2019, DOI: 10.1057/s41599-018-0212-7

[2] Impacts of Mismanaged Trash. EPA, 2020. Available at https://www.epa.gov/trash-freewaters/impacts-mismanaged-trash (accessed)

[3] Mekonnen T., Mussone P., Khalil H., Bressler D. Progress in bio-based plastics and plasticizing modifications. J. Mater. Chem. A, 1, 2013, pp. 13379-13398. DOI: 10.1039/C3TA12555F

[4] European Bioplastics: What are bioplastics? [online] [21.03.2021] Available at https://docs.european-bioplastics.org/publications/fs/EuBP_FS_What_are_bioplastics.pdf (2018).

[5] Zaimis U., Jurmalietis R., Jansone A. Processed seaweed and winemaking waste co-fermentation for biogas extraction: pilot study. Engineering for Rural Development, 2018, pp. 1916-1919. DOI: 10.22616/ERDev2018.17. N497

[6] Prajapati P.M., Maheriya G.K., Jani G.K., Solanki H. Carrageenan: A natural seaweed polysaccharide and its applications. Carbohydrate Polymers, 105 (1), 2014, pp. 97-112. DOI: $10.1016 /$ j.carbpol.2014.01.067

[7] Tuvikene R., Truus K., Robal M., Volobujeva O., Mellikov E., Pehk T., Kollist A., Kailas T., Vaher M. The extraction, structure, and gelling properties of hybrid galactan from the red alga Furcellaria lumbricalis (Baltic Sea, Estonia). Journal of Applied Phycology, 22(1), 2009, pp. 51-63. DOI: $10.1007 / \mathrm{s} 10811-009-9425-\mathrm{x}$

[8] Sedayu B.B., Cran M.J., Bigger S.W. A Review of Property Enhancement Techniques for Carrageenan-based Films and Coatings. Carbohydrate Polymers, Volume 216, 2019, pp. 287-302, ISSN 0144-8617. https://doi.org/10.1016/j.carbpol.2019.04.021

[9] Wilson A.S. Plasticizers. Principles and practice, Vol. 585, The Institute of Materials, London, 1995.

[10] Baltacioğlu H., Balköse D. Effect of zinc stearate and/or epoxidized soybean oil on gelation and thermal stability of PVC-DOP plastigels. J Appl Polym Sci, 74 (10) (1999), pp. 2488-2498. DOI: 10.1002/(SICI)1097-4628(19991205)74:10 < 2488::AID-APP18 > 3.0.CO;2-B 